\title{
El romance adolescente. Un análisis sociológico de la política afectivosexual en la adolescencia
}

\section{Mar Venegas}

Universidad de Granada. Facultad de Ciencias de la Educación. Departamento de Sociología mariter@ugr.es

\section{Resumen}

El análisis sociológico del romance adolescente se inicia en el marco de los estudios culturales de los años setenta del siglo XX, sin llegar a consolidarse como línea de investigación. Desde la década de 1990, la sociología desarrolla una línea de trabajo sobre amor y sexualidad de interés para el estudio del romance adolescente. El presente artículo enlaza con la exploración acerca de esa temática en el marco de dichas contribuciones teóricas. A partir de ellas, es definido como espacio social y cultural constituido por las siguientes dimensiones que guían la investigación: la cultura de clase, género y etnia; el grupo de amistad; la atracción sexual; las prácticas sexuales; y las prácticas afectivas y la formación de pareja. Con este marco de fondo, el objetivo del artículo es analizar dichas dimensiones constitutivas del romance adolescente para conocer los modelos de masculinidad y feminidad presentes en él y, por ende, el tipo de relación que se establece en torno a estos modelos en términos de poder y (des)igualdad. Los datos en los que se profundiza proceden de un análisis basado en dos estudios de caso realizados en la ciudad de Granada (Andalucía, España). El examen muestra la tendencia de los chicos hacia una masculinidad hegemónica o viril, mientras que las chicas tienden a la feminidad del amor romántico. Del análisis se concluye la persistencia de un doble estándar de género, donde masculinidad y feminidad se complementan en el romance adolescente según una lógica patriarcal, desigualitaria, que dificulta la formación de relaciones democráticas, basadas en el respeto mutuo y la igualdad.

Palabras clave: romance adolescente; género; amor; sexualidad; adolescencia 
Abstract. Adolescent romance: A sociological analysis of the politics of young people's sexuality and relationships

The sociological study of adolescent romance began with cultural studies in the 1970s. However, it was not a consolidated line of research until the 1990s, when love and sexuality became a topic of interest for the study of adolescent romance in the field of sociology. This article investigates adolescent romance in the framework of these theoretical contributions, which define it as a social and cultural space consisting of the following dimensions: the culture of class, gender and ethnicity, friendship groups, sexual attraction, sexual practices, and affective practices and couple formation. Within this framework, the objective of this paper is to analyse the dimensions that define adolescent romance in order to identify the models of masculinity and femininity present in it. Based on this analysis, the type of relationship established in terms of power and (in)equality is studied. The data were drawn from two case studies carried out in the city of Granada (Andalusia, Spain). The data show the tendency of boys toward hegemonic or virile masculinity, while girls tend to embrace romantic love. Drawing on this analysis, the paper concludes that a gendered double standard persists where masculinity and femininity are complementary in adolescent romance following a patriarchal logic that hinders the formation of democratic, egalitarian relationships based on mutual respect.

Keywords: adolescent romance; gender; love; sexuality; adolescence

\section{Sumario}

1. Amor, sexualidad y romance

2. Metodología de la investigación

3. El romance adolescente: análisis y discusión de los resultados
4. Conclusiones

Referencias bibliográficas

\section{Amor, sexualidad y romance}

El romance ha sido un tema de investigación residual para la sociología, especialmente en España. Hasta la década de 1990 no encontramos en sociología una línea de investigación sólida en torno a amor y sexualidad, en la que se puede insertar el estudio del romance. Esta línea parte del análisis de las modificaciones acontecidas en el nivel microsociológico de las relaciones y de las prácticas, «la transformación de la intimidad» (Giddens, 2004), para explicar los grandes cambios macrosociológicos y estructurales que tienen lugar durante el siglo XX y se prolongan hasta la actualidad (Beck y Beck-Gernsheim, 2001, 2012; Giddens, 2004; Gómez, 2004; Bauman, 2005; Bourdieu, 2005; Castells y Subirats, 2007; Carmona, 2011; Venegas, 2013a):

- Cambios derivados de la incorporación de las mujeres a la educación formal y, con ello, al mercado laboral, con lo que protagonizan importantes procesos de movilidad profesional. 
- Cambios en la sexualidad, gracias a una liberación concretada en el uso de métodos anticonceptivos y nuevos valores sexuales que hacen posible la separación entre amor, sexualidad, reproducción y placer.

- Cambios en los modelos de familia, con el aumento de los divorcios, las familias recompuestas, los hogares monomarentales y monoparentales, las parejas de hecho, el matrimonio entre personas del mismo sexo y el cambio de nombre en el DNI de personas transexuales.

- Cambios en los modelos de afecto, cuya clave está, ahora, en compatibilizar libertad, igualdad, autonomía e independencia con amor y sentido de pertenencia.

El resultado de esos cambios es, según señala la literatura disponible, la fugacidad en las relaciones de pareja, la falta de compromiso, los fallos de comunicación (Bauman, 2005) o la individualización creciente, principalmente entre las clases medias (Beck y Beck-Gernsheim, 2001; Bauman, 2005; Urrea et al., 2006; Carmona, 2011). Estos avances teóricos sobre amor y sexualidad en las parejas, desde un enfoque de género, se refieren, por lo general, a la edad adulta, quedando fuera del análisis las relaciones en la adolescencia, que es, sin embargo, el período de iniciación de las relaciones afectivosexuales.

Por su parte, los primeros estudios en torno al romance adolescente datan de la década de 1970, en el marco de los estudios culturales. Sus aportaciones son fundamentales para la observación acerca del romance, si bien no podemos afirmar que se haya consolidado una línea de investigación sobre este tema con posterioridad a dichos estudios. Así, desde la llamada teoría de la resistencia, Paul Willis (1988) será pionero en el análisis de las prácticas de resistencia al sistema educativo (y social) de los chicos de clase obrera que, en última instancia, suponen el análisis de la construcción de su masculinidad de clase. Unos años más tarde, Willis (2003) actualiza su análisis sobre la masculinidad juvenil de clase obrera a la luz de los cambios sociales acontecidos desde la década de 1970. Sin embargo, Willis no incorpora a las chicas en su estudio, vacío que es criticado por Angela McRobbie (1978), quien extiende ese análisis materialista de la cultura a las chicas adolescentes y jóvenes de clase obrera que, según ella, encarnan la cultura patriarcal de su entorno. McRobbie señala la solidaridad del grupo de pares y la «ideología del romance» como los dos espacios de resistencia de estas chicas frente al «rol femenino tradicional», al que ellas se adaptan convirtiéndose en objeto de atracción de los chicos. En estos espacios, el modelo de género queda anclado en la cultura de clase:

La cultura de las chicas adolescentes de clase obrera puede ser vista como una respuesta a las condiciones materiales impuestas sobre ellas como resultado de su posición de clase, pero también como indicador y respuesta de su opresión sexual como mujeres. Ambas están salvadas y cerradas dentro de la cultura de la feminidad. (P. 108) ${ }^{1}$

1. Traducción del original en inglés al castellano realizada por la autora de este artículo. 
Así pues, la resistencia es una estrategia de construcción de significados que dota de sentido a la vida cotidiana frente a las determinaciones estructurales de clase y género. La resistencia es una producción cultural que toma, en este caso, la forma de ideología del romance. Ahora bien, como señalan las teorías de la resistencia, dicha producción de significados conduce, en última instancia, a la reproducción de la posición social de partida.

Esta línea de análisis es retomada más tarde por Holland y Eisenhart (1990) en su «cultura del romance». También ellas observan que es el grupo de pares el que introduce a las mujeres en un mundo de romance donde ser atractivas para los hombres resulta fundamental. Es lo que llaman «sexual auction block» (p. 8), que podríamos traducir como espacio de la subasta sexual ${ }^{2}$. La paradoja radica, según Weiler (1988, cf. Holland y Eisenhart, 1990), en que las chicas se benefician del atractivo sexual para escapar, mediante la fantasía o el matrimonio, a la pesadez de la escuela o del trabajo, una resistencia al mundo capitalista que, a largo plazo, se traduce en un recrudecimiento de la cultura patriarcal. Con ello se continúa con el debate abierto por McRobbie (1978) sobre si la cultura del romance y las relaciones sexuales son realmente un intento por resistir a la subordinación o si, como plantea Giroux (1983a, cf. Holland y Eisenhart, 1990), son parte del problema. Las autoras pretenden superar estas limitaciones y contradicciones de la teoría de la resistencia optando por la teoría de la práctica, y proponen seguir estudiando la forma en que mujeres y niñas responden al sexismo y compararlo con otros grupos en desventaja.

Los estudios de McRobbie (1978) y Holland y Eisenhart (1990) constituyen el principal referente teórico de este trabajo. En los quince años posteriores a este segundo estudio no ha habido una amplia producción de investigación y conocimiento sobre el romance adolescente desde la sociología (sí más desde la psicología y la psicología social, disciplinas que quedan fuera del alcance de este estudio), salvo algunos trabajos (Gómez, 2004; Urrea et al., 2006; Clair, 2007a, 2007b; Jones, 2010; Carmona, 2011). La revisión de todos estos textos y sus aportaciones permite proponer una definición de romance adolescente como un espacio social y cultural constituido por una serie de dimensiones que guían el análisis de la investigación presentada en este artículo, a saber:

- La cultura de clase, género y etnia.

- El grupo de pares o grupo de amistad.

- La atracción sexual.

- Las prácticas sexuales.

- Las prácticas afectivas y la formación de pareja.

El artículo parte de esta definición para analizar el romance entre las adolescentes y los adolescentes del estudio. El romance es, en definitiva, el espacio

2. En esta propuesta se observa un paralelismo con las teorías del intercambio (Lévi-Strauss, 1969; cf. Rubin, 1975), del tráfico (Rubin, 1975) o del intercambio de los bienes simbólicos (Bourdieu, 2005). Para saber más sobre esta cuestión, véase Venegas (2010). 
sociocultural que comprende las relaciones y las prácticas afectivosexuales. Lo afectivosexual ha sido ampliamente investigado desde la perspectiva educativa, pero para el estudio del fenómeno sociológico es necesario definir un objeto de naturaleza sociológica. Por otro lado, a diferencia de trabajos como los de Willis (1988, 2003), McRobbie (1978) y Holland y Eisenhart (1990), centrados en el análisis de chicos, el primero, y chicas y mujeres, los segundos, esta investigación toma como unidad de análisis las relaciones de género, que, como ha señalado ampliamente la literatura feminista (Connell, 1987, 2002; Butler, 1997; Skeggs, 1997), están mediadas por el poder. Por ello se ha buscado un concepto de naturaleza sociológica que pudiera remitirnos al estudio de relaciones y de prácticas afectivosexuales socioestructuralmente contextualizadas. De ahí la opción por el término politics procedente de la literatura feminista anglófona (sexual politics, gender politics), que se refiere a «the principles relating to or inherent in a sphere or activity, especially when concerned with power and status" (Soanes y Stevenson, 2008: 1110). Traducido como politica afectivosexual, este término ofrece un espacio conceptual de naturaleza sociológica, al partir de la consideración de que el poder está presente en todas las relaciones y estructuras sociales (Connell, 2002), así como en los discursos (Foucault, 1989; Butler, 1997), a lo que la literatura revisada se refiere también en términos de «negociación sexual» (Carmona, 2011). Así pues, la política afectivosexual se define en esta investigación como el «conjunto de principios, mediados por el poder, relativos a las relaciones afectivosexuales, que se concretan en cuatro dimensiones relacionales: género, sexualidad, afectividad y cuerpo» (Venegas, 2011a: 565) $)^{3}$.

Cabe hacer una última consideración sobre la literatura revisada. Al describir los modelos de masculinidad y feminidad dominantes, esto es, caracterizados por un sistema patriarcal de dominación de género, encontramos dos referentes de interés para este trabajo. Connell (1987) habla de «masculinidad hegemónica» y de «feminidad enfatizada», donde Bourdieu (2005) habla de «virilidad como nobleza» $\mathrm{y}$ «ser femenino como ser percibido». La masculinidad se define como virilidad y dominación; la feminidad, como subordinación y construcción de una subjetividad a través de la percepción de una mirada masculina garante de los valores tradicionales de virilidad. Esa mirada normativa de un otro masculino (Venegas, 2006) está presente también en el análisis de la feminidad que hacen McRobbie (1978) y Holland y Eisenhart (1990). Se trata, en definitiva, de un análisis sobre la desigualdad de género en el seno de la política afectivosexual.

Con este marco teórico de fondo, el objetivo del presente artículo es analizar las dimensiones que constituyen el romance adolescente para conocer los modelos de masculinidad y feminidad presentes en él y, en consecuencia, el tipo de relación que describen esos modelos en términos de poder y (des) igualdad.

3. Para conocer en mayor profundidad la construcción teórica y epistemológica del término política afectivosexual, véase Venegas (2011a). 


\section{Metodología de la investigación}

Para investigar la política de las relaciones afectivosexuales adolescentes, un objeto de estudio de difícil acceso para la investigación social, se han seguido las experiencias presentes en la literatura revisada (Urruzola, 1991; Barragán, 1999; Gorrotxategui y De Haro 1999; Gómez, 2004), que optan por una metodología de investigación-acción, desde el respeto por la persona (Reiss, 2005) y la consideración de la agencia social de los sujetos (Venegas, 2011a, 2011b, 2013a).

La pertinencia de esta metodología para investigar la política afectivosexual radica en la necesidad de reflexionar, desde la investigación sociológica, sobre el objeto de estudio (la política afectivosexual), mediante la praxis de ese objeto de estudio (educando las relaciones afectivosexuales), facilitando el acceso a la intimidad de los sujetos. Ahora bien, esta orientación aplicada de la investigación no exime de, ni es incompatible con, un trabajo epistemológico y ontológico sistemático y científico (Venegas, 2011c). Esta propuesta está próxima a la investigación-acción colaborativa de Elliott $(1993,1994)$ y al planteamiento de Kemmis (2007) sobre la investigación-acción como una práctica para el cambio de prácticas: "práctica, prácticos/as, y condiciones de la práctica son transformadas tanto como reproducidas de una ocasión a otra» (Kemmis 2007: 5) ${ }^{4}$.

Esta metodología permite, pues, dar cobertura al objetivo general de la investigación (exploratoria), que consistía en analizar los valores, las normas y las prácticas sobre género, sexualidad, amor y cuerpo, para estudiar los procesos de socialización y subjetivación que tienen lugar en torno a ello en la adolescencia, como procesos microsociológicos que se corresponden con procesos macrosociológicos de reproducción y cambio, respectivamente, teniendo en cuenta las perspectivas comparativas de clase social, género y etnia.

La tesis de partida de la investigación relativa al objeto de este artículo es que clase social, género y etnia establecen los parámetros estructurales de la política afectivosexual adolescente que delimitan los modelos de masculinidad y feminidad existentes en ella. El análisis que presenta este artículo aborda esta tesis de investigación.

El trabajo de campo se ha realizado en dos colegios de sendos barrios de la ciudad de Granada (Andalucía, España), uno de clase obrera (curso 20052006), y otro de clase media ${ }^{5}$ (curso 2006-2007), en concreto el grupo clase de cuarto de ESO de ciencias sociales y humanas de cada colegio, considerados como dos estudios de caso, al tratarse de una «recogida sistemática de información suficiente sobre un contexto social [...] particular [...] de manera que permita a quien investiga entender efectivamente cómo opera o funciona» (Berg, 2001: 225) ${ }^{6}$. Con ello, lejos de buscar conclusiones generalizables, se han buscado dinámicas subyacentes a cada caso, tal como señala Elliot (1993).

4. Una versión más amplia de la metodología de investigación acción de esta investigación puede encontrarse en Venegas (2011b).

5. Se ha seguido la clasificación hecha por el Ayuntamiento de la ciudad en función de las características socioculturales y demográficas de los barrios.

6. Traducción del original en inglés al castellano realizada por la autora de este artículo. 
La investigación comprende dos fases. Cada fase se corresponde con una técnica de producción de datos. Se ha empezado diseñando e implementando un curso de diez sesiones sobre educación afectivosexual en el aula, en horario de tutorías, a partir de la pasación de un cuestionario de evaluación inicial (Venegas, 2014). Todas las sesiones han sido grabadas, evaluadas y analizadas.

A continuación, se ha empleado la técnica de la entrevista personal, semiestructurada y en profundidad (Valles, 1997), cuyo protocolo se ha diseñado a partir del marco teórico de la investigación (Venegas, 2011a). Para acceder a toda la población de cada caso, se ha entrevistado a cada miembro de los dos casos estudiados. En total son 42 sujetos: 12 chicas y 30 chicos de entre 15 y 18 años. El caso de clase obrera se compone de 7 chicas y 7 chicos. El de clase media tenía una sobrerrepresentación de chicos, 23, frente a 5 chicas, por lo que un primer análisis de esas 23 entrevistas ha permitido seleccionar 8 como las representativas del caso.

La primera fase de la investigación ha sido clave para el desarrollo de la segunda, al facilitar el acceso a la intimidad de los sujetos. El nivel de detalle y profundidad de las entrevistas personales no hubiera sido factible de no haber contado con esa fase previa de trabajo en el aula. A su vez, esas prácticas educativas han permitido delimitar mejor el protocolo de entrevista, así como triangular datos relativos a las dimensiones de la política afectivosexual. Si el análisis de las dinámicas de grupo y los debates en clase han permitido acceder al imaginario colectivo adolescente sobre el fenómeno investigado, las entrevistas personales han hecho posible, partiendo de ese imaginario colectivo, profundizar en la experiencia individual. Además, como investigación-acción, este proyecto contenía en sí mismo también el valor aplicado de la investigación social en el ámbito educativo, en tanto que práctica para el cambio de prácticas. Acción educativa e investigación sociológica se han ido retroalimentando a lo largo de los siete años que ha comprendido este proyecto, con un total de tres años de trabajo empírico en los dos centros educativos antes mencionados.

Este artículo tiene como objetivo analizar solamente los datos de las entrevistas relativos a las dimensiones que definen el romance adolescente, antes señaladas, no para elaborar conclusiones generalizables, sino para explorar las dinámicas subyacentes a cada caso. El tratamiento de las entrevistas se ha llevado a cabo mediante el programa NVivo para análisis cualitativo. Las relaciones investigadas son todas heterosexuales, pues así las han referido los sujetos de la investigación en las entrevistas.

\section{El romance adolescente: análisis y discusión de los resultados}

\subsection{La cultura de clase, género y etnia}

Como en estudios anteriores (McRobbie, 1978; Willis, 1988; Holland y Eisenhart, 1990), esta investigación evidencia que clase social y género moldean las experiencias de los sujetos en el romance adolescente, pues ocupan un espacio central en el devenir sujeto (Skeggs, 1997; Youdell, 2006; Venegas, 2017). Esta 
investigación incorpora, además, la pertenencia étnica. La siguiente cita ilustra la presencia de estos tres principios de estructuración social en el romance adolescente ${ }^{7}$ :

Me arrepiento [...] No te voy a contar, porque me da vergüenza [...] Ella es más adelantá que yo [...] Me puso la mano en las partes prohibidas de las niñas [...] Yo digo: «Si me ha dejao que le toque esto, me dejará que le toque otras cosas" [...] Yo creo que la primera vez de ella no ha sío, ¡eh! Porque no le salía sangre ni ná de eso [...]. Luego me sentí sucio. [...] Es como si yo sintiera que no lo tenía que haber hecho, porque no la quiero. No... no. Yo sé que mi vida no la voy a compartir con ella [...]. No fue como las parejas, que se ponen... [...]. No era lo que yo creía. [...] Yo nunca hubiera abusao de ella. Yo con eso soy muy cuidadoso [...]. Es sucio y no hice apenas ná. [...] Yo placer no sentí. Yo sentí que, que eyaculé, y ya está. Pero ella tampoco tuvo que sentir ná, ¿no? Porque se echa un agua, ¿no? [...] Pero es que, cuando estoy con ella, me siento bien y me gusta. ¿Qué es lo que me pasa? [...] No la quiero. A lo mejor, la dignidad se la he quitao yo y yo no le correspondo. ¿`Tú me entiendes? Por eso me siento sucio. (Raúl ${ }^{8}, 17$ años, clase obrera, mestizo)

Los valores, las creencias, las normas, los prejuicios y los estereotipos presentes en esta cita dan cuenta de una socialización en un modelo de género (la masculinidad), de clase (la obrera) y de etnia (predominantemente la gitana) que orienta las prácticas de los sujetos que viven en este contexto, donde la sexualidad, según los datos observados en las entrevistas, es considerada tabú, legítima solo en relaciones estables donde hay amor (también en Carmona, 2011); los genitales suelen ser denominados con eufemismos; «la primera vez» (esto es, la primera relación coital) es idealizada y estereotipada, y la práctica de la sexualidad se entiende como algo espontáneo, que no requiere de aprendizaje. Este modelo podría explicar la frustración de los sujetos socializados en él, cuando sus primeras experiencias sexuales coitales, lejos de ser «lo que yo creía», resultan carentes de placer. La socialización bajo valores sexuales patriarcales como «la dignidad» (o sea, honor, virginidad y honra) lleva a vivir la mezcla entre amor, deseo, frustración y arrepentimiento con malestar. Así se ha visto en este análisis, como en otros similares (Urrea et al., 2006; Carmona, 2011), donde la socialización sexual marcadamente patriarcal es más frecuente en contextos de clase obrera, y su frecuencia se observa también entre la población de etnia gitana del estudio. En la misma línea, se observa la centralidad de la virginidad de las chicas en el contexto de clase obrera y etnia gitana del estudio: perder la virginidad suele implicar un conflicto familiar fuerte, especialmente cuando los padres no aceptan a la pareja de su hija:

7. En lo que sigue, el análisis de las entrevistas se acompaña de verbatims procedentes de las mismas y que contienen los datos ilustrativos del análisis.

8. A fin de mantener el anonimato de las personas entrevistadas, todos los nombres utilizados aquí son ficticios. Para cada sujeto, se señalan nombre, edad, clase social y pertenencia étnica. 
Ha habío muchos problemas en mi casa, [...] me han echao muchas veces de mi casa. [...] Cuando empecé con este niño, pues mala [experiencia], porque me hubiera gustao no haberlo hecho, no haber cometío ese error. (Yoli, 17 años, clase obrera, gitana)

En el caso de clase media, varias entrevistas dan muestra de cierto cuestionamiento de este modelo de sexualidad patriarcal y estereotipado:

«¡No, un beso no, que me puedo quedar embarazá!». Y le digo: «¿Que te quedas...?». ¡Uf? Y he oído cosas... Que si se sentaba en la misma silla (eso se lo dicen los padres, ¿verdad?), que si te sientas en la misma silla que otro, conmigo, que te puedas quedar embarazá. Y le digo: «No te lo creas». O que si te haces una pajilla, que te quedas ciego, y yo: «Eso no pasa. Mira todos como ven. Que los ciegos no es que estén enganchaos, que es que tienen un problema de vista, ¡joé!». Entonces, oyes cada cosa. [...] "Que mi novio me ha hecho sexo oral y no sé si me puedo quedar embaraza», y dices: "¿Qué me estás contando?». La gente que tiene todavía una mentalidad mu... (Alberto, 15 años, clase media, caucásico)

La tendencia hacia una sexualidad que se vive de forma más libre y abierta, hallada en varias entrevistas del caso de clase media, podría alinearse con las posturas que señalan un proceso de individuación creciente entre las clases medias (Beck y Beck-Gernsheim, 2001; Bauman, 2005; Carmona, 2011).

Clase, género y etnia se muestran en las entrevistas como los vectores que definen los proyectos vitales de estas y estos adolescentes (también en McRobbie, 1978; Holland y Eisenhart, 1990; Urrea et al., 2006), estableciendo las condiciones materiales en que se configuran sus formas de relación (Moreno, 2008, cf. Carmona, 2011). Un fenómeno clave observado en las entrevistas de esta investigación es que cuanto más alta es la posición del sujeto en la estructura de clases, más se proyecta la carrera educativa a largo plazo, incluyendo estudios universitarios, lo que pospone la formación de familia: "Hay cosas más importantes que eso [la pareja], por ejemplo: lo que estudias» (Jose, 15 años, clase media, caucásico). La proyección de los estudios, la formación de pareja y otros proyectos vitales relacionados ocupan un lugar central en estos procesos (también en McRobbie, 1978; Holland y Eisenhart, 1990). Las entrevistas realizadas en el caso de clase obrera ofrecen una visión diferente al testimonio anterior:

CARMEN (15 años, clase obrera, gitana): Una amiga mía, el año pasao estaba en esta escuela y, claro, tenía un novio, y el novio se la llevó, se la llevó, ¿̨no? dicen. Y ahora la ha dejao preñá, y ahora la niña vive con su novio. Y ya tiene el niño y tó. Y ahora, el niño, la niña está, claro, ya está casá con él, ¿no? Claro, con su familia será. Ahora, el niño está tol día gamberreando por ahí y la niña está harta cuernos, con el niño y en la casa. Y ahora el novio por ahí.

ENTREVISTADORA: ¿Y eso es frecuente en el barrio?

CARMEN: Con ella yo conozco a dos, sí. Es que ná más que con que te cases ya con tu edad, ¿qué haces? Ya no disfrutas. Tienes una niña con 15 años casá. 
Y el novio tol día gamberreando. Claro, yo pa mí que le pega y tó, porque yo veo a la niña con moraos y tó.

En las entrevistas donde aparece un romance temprano entre las chicas de clase obrera, más frecuentemente entre las de etnia gitana, este ocupa el lugar que debería de ocupar la importancia de la educación formal en la configuración del proyecto vital (también en McRobbie, 1978; Holland y Eisenhart, 1990; Urrea et al., 2006), donde se dibuja una paradoja: el romance confiere prestigio y estatus en el grupo de amistad, pero la falta de formación anula las posibilidades de emancipación, asertividad y autoestima de las chicas. El resultado es la reproducción de un modelo de relación patriarcal, en que se ha observado, a veces, una potencial situación de violencia de género.

La sociología de la educación ha mostrado que la prolongación de los estudios retrasa la formación de pareja y de familia. En este estudio, se ha observado que, para la clase obrera, es una posibilidad de movilidad social ascendente, mientras que para la clase media legitima su reproducción social. Así, cuando Bárbara habla del tipo de chico que busca para formar una familia en el futuro, señala que:

Me insinúan [sus padres], como diciendo: «Búscate un novio en la universidad, cuando ya estés en la universidad, porque ahí es donde vas a encontrar a lo mejor, a tus amigas mejores, a tu pareja». Dice [su madre]: «Pero hombre, tampoco te voy a decir, a mí no me gusta que me traigas a la casa a un barrendero, porque si lo quieres, lo quieres, y eso... Que me traigas a un yo qué sé, a un médico. Que eso me da igual. Mientras seas tú la que lo quiera, no sé qué». Me dice: «hombre». Como diciendo, como diciendo [ríe]: «Si me traes a alguien que esté más...», dice: "pos mejor». (Bárbara, 15 años, colegio de clase obrera, caucásica)

Pero Bárbara no quiere ir a la universidad, quiere ser peluquera. En general, las entrevistas muestran que la posibilidad de elegir y proyectar está muy determinada por la posición de clase. Se ha observado que una socialización que permite romper con las normas tradicionales promueve un pensamiento más abierto, indicativo de cambio social. Un claro ejemplo de ello lo ofrece la entrevista con una de las chicas del colegio de clase media, que procede de una familia con una posición económica bien acomodada, donde madre y padre desarrollan profesiones liberales de alta cualificación:

Yo, de chica, pues decía que no me quería casar y que yo quería tener a mi niña de los congelados [...] Paso de casarme, así es que yo tengo mis novios y eso, pero yo quiero vivir con mis niños y que no tenga que depender de un padre y por eso la quiero congelada. (Victoria, 15 años, clase media, caucásica)

Victoria no cuestiona la maternidad, pero el hecho de que proyecte una maternidad autorreferencial, sin necesidad de una pareja estable que le ayude a procrear, es indicativo de cambios en el modelo de género (feminidad, mater- 
nidad) que, según la tesis de partida de este artículo, están estrechamente vinculados a la pertenencia étnica y de clase de los sujetos.

\subsection{La atracción sexual}

Según los datos procedentes de las entrevistas, la atracción-elección describe un espacio similar al de la "subasta sexual» (Holland y Eisenhart, 1990) o el «mercado de los bienes simbólicos» (Bourdieu, 2005), donde las chicas parecen priorizar su cuerpo como objeto de atracción, mientras que los chicos enfatizan sus bienes materiales:

Yo creo que también me influye mucho el qué dirán de la gente, ¿no? No me influye muchísimo, pero yo creo que también te puede influir, porque, a lo mejor, si tú te arreglas, y tú te ves guapa o lo que sea y luego sales a la calle... «Ay, pues mira, que te has puesto el rosa con el azul, y esto con lo otro no pega.» Tienes que tener un poco de decir: «Pues mira, pues habré hecho eso», pero también tienes que decir por dentro: «Pues si a mí me gusta, ¿por qué no lo voy a llevar puesto? ¿ ¿No?». Y, si te arreglas, yo qué sé. Si me arreglo, pienso más en la persona con la que voy a estar, para que me vea mejor, más guapa. (Mónica, 16 años, clase obrera, caucásica)

Que le han dicho a la niña sin venir a cuento, pa llamar la atención: «Es que tengo moto» [...]. ¿Es que tú, aunque tengas moto, eres más guapo o eres más feo? [...] Tonterías de que te quedas flipao. [...] Yo no puedo con ese niño que llegue a la puerta del colegio un día y me diga: «Déjame la moto que le dé una vuelta a la niña», y cogerla un momentillo y te la llevas tú pa que te dé una vuelta a ningún sitio. ¿Pa qué quieres la moto? [...] Hay mucha gente por ahí que vacila de cosas que no tienen. (Javi, 17 años, clase media, caucásico)

Esas marcas diferenciales de género evidencian la mirada normativa de un otro, masculino, que representa el control que ejercen las normas de género sobre el amor, la sexualidad y el cuerpo, principalmente sobre los sujetos mujer (Venegas, 2006). Las chicas del caso de clase obrera de esta investigación denuncian sentirse vigiladas, sentir que fallan o sufrir el qué dirán (Skeggs, 1997), sobre sus cuerpos (Bartky, 1988) o su relación con el modelo ideal de belleza (Wolf, 1991). Un «ser femenino como ser percibido» (Bourdieu, 2005), para el que resulta difícil romper con las normas.

Así, las entrevistas muestran una secuenciación diferente según se trate de chicos o chicas. Los chicos dan prioridad a la atracción física: «Lo primero que te atrae es el físico, ¿no? Luego también cómo sea, porque, a lo mejor, está mu buena, pero si es una antipática y de tó, nada» (Jorge, 16 años, clase obrera, caucásico). Para las chicas, en cambio, la atracción corporal se muestra en los datos como consecuencia de la atracción personal:

Mi expareja es totalmente distinto [a mi modelo ideal]... No es un niño que diga: «iQué guapo!», pero empezó a gustarme por cómo era, por cómo me 
llevaba con él [...]. Como yo lo quería, tampoco me importaba demasiao. [...] Dices: "Ahora lo veo hasta guapo». (Mónica, 15 años, clase media, caucásica)

Por otro lado, los datos dan muestra también de una orientación hacia experimentación y placer sexuales mayor entre los chicos que entre las chicas: «Ahora mismo, buscas una niña guapa [...] Pero muchas veces solo quieres a esas mujeres pal tema del sexo" (Jose, 15 años, clase obrera, caucásico), con lo que se posterga la estabilización de la pareja a una edad más avanzada:

Sexo sin compromiso. Te ves una vez, pun, lo haces y te olvidas. Po sí, ahora mismo, sí. [...] Por lo menos con veinticinco o por ahí ya empezaré a decir: «Bueno, vamos a ponernos serios, ya el tonteo, ya se acabó». [...] Ahora, hay más niñas, es la época de conocer a más niñas y de ir conociéndote tú a ti mismo a través de ellas. (Alberto, 15 años, clase media, caucásico)

\subsection{El grupo de amistad}

El grupo de amistad (o grupo de pares) delimita un espacio central en la construcción de género y sexualidad en la adolescencia, así como del propio romance adolescente (McRobbie, 1978; Willis, 1988; Holland y Eisenhart, 1990; Reiss, 2005; Holfve-Sabel, 2011; Messer et al., 2011), por lo que su análisis requiere una atención especial (Venegas, 2013b) a partir de los datos de las entrevistas. Define los márgenes del control y la construcción de la norma entre sus miembros (Clair, 2007a, 2007b). Establece procesos de liderazgo en función de la experiencia sexual (Korkiamäki, 2011; Venegas, 2011c, 2013b). Para las chicas, ofrece apoyo afectivo y un aprendizaje compartido sobre sexualidad (McRobbie, 1978; Holland y Eisenhart, 1990). En los chicos, se construye en torno a la «masculinidad hegemónica» (Connell, 1987) o «virilidad como nobleza» (Bourdieu, 2005). De este diferencial de género, patriarcal, se derivan muchos de los procesos conflictuales implicados en el romance adolescente dentro del grupo de amistad que han sido hallados en las entrevistas:

Discusiones porque no te pongas esa farda $[\ldots]$ si yo estoy contigo no me gusta que te pongas una farda [...] vayas enseñando ahí tó. Que prefiero un pantalón, que no lo prohíbo pero que en pantalón se va más a gusto [...]. Por ejemplo, vas a la discoteca, si vas con tu novio y llevas falda, o una de dos, o estás tol día bailando con ella, o te estás arriesgando a tener una pelea, porque a lo mejor tu novia no va en busca de ná, pero si a lo mejor hay alguno que está más bebío y se sobrepasa con ella... (Jose, 15 años, clase obrera, caucásico)

Según los datos analizados, celos, posesión, control y otros conflictos en la pareja reflejan la necesidad de los chicos de imponer su autoridad para mantener el respeto y el liderazgo en el grupo de amistad, donde la sexualidad define las jerarquías de prestigio y poder. En esas dinámicas, los datos suelen mostrar a los chicos como sujetos de deseo, mientras que las chicas aparecen más bien como objetos de deseo. Esos datos muestran la pervivencia de un 
modelo patriarcal que se manifiesta en dos sentidos opuestos. Uno, relativo a los modelos femeninos de deseo sexual en el grupo:

Estaba así bailando y dice mi amigo: «Esa está buena». Y yo: «Será pa ti». Porque si se lía con una que es un cardo y está to borracho, le iba a caer una durante to el año impresionante; hasta que se me olvide: «Que tas comío una más fea que tó». Así se iba tranquilo. [...] Entre los amigos sí decimos que si es fea: «La vín, qué fea es esa, no sé qué» y tú vas y te la comes, pos «compae, tú eres tonto». (Tony, 17 años, clase media, mestizo)

Otro, huyendo precisamente de esos modelos al dar prioridad a un tipo de chica «más invisible» y que, por tanto, no suele ser objeto de deseo masculino:

A mí nunca me gustan las niñas mu perfectas, que van como si fueran las reinas. A mí me gustan rellenicas, que sean normales. [...] No una de esas que van por ahí y se fijan tós en ella. Una persona que no llame la atención, que sea pa ti solo, $[\ldots]$ que no vayas ahí con la gente y se metan tó los niñatos: «GGuapa!, no sé qué», que vayas con ella, que no presumas de niña, que sea como a ti te guste, no como te digan los demás. [...] Aunque la niña sea mu guapa y el niño sea mu guapo, pa que digan los niños: «Ná más que usarla y ya está». (Guillermo, 17 años, clase obrera, caucásico)

Las entrevistas muestran también cómo esta masculinidad hegemónica o viril ejerce una presión sobre los chicos hacia la negación y ocultación de sus sentimientos:

La [pareja] que yo tengo ahora, le cuesta [...]. Me decía que no me quería querer ni que yo le quisiese a él [...]. Que te demuestre lo que se ha guardado porque no quería decírtelo, aunque en verdad lo ha sentido pero ha intentado demostrar otra cosa y que ahora ya podía... Un poco tonto. (Laura, 18 años, clase media, caucásica)

Según se observa en las entrevistas, esta masculinidad patriarcal se despliega en la adolescencia a dos niveles. Por un lado, mediante actitudes homófobas, más presentes entre los chicos que entre las chicas de la investigación, sobre todo de clase obrera: la masculinidad es virilidad y no se aceptan divergencias. Por otro lado, en la restricción de la libertad de sus parejas, reproduciendo esquemas de dominación y subordinación con un doble estándar de género:

Estábamos en la discoteca en el viaje de estudios y se subió a la barra. Eso a mí no me hizo gracia. [...] No ha podío ser [...] porque se ha abrazao a otros niños. Yo sé que son sus amigos y que es normal, pero no me gusta. [...] Si yo le doy un abrazo a una niña, ellas son como mis hermanas. [...] Y yo noto que no me quiere, porque si me quisiera de verdad, ya vería lo que hace. (Raúl, 17 años, clase obrera, mestizo)

Pese a ello, algunas chicas ofrecen muestras de resistencia a través de prácticas que afirman su autonomía: «Mi novio me dice: "Eso no me gusta, no te 
lo pongas", y yo le digo: "Si no te gusta, pues no lo mires"» (Belén, 15 años, clase media, caucásica).

Las entrevistas muestran que el grupo de amistad es también el espacio de experimentación para definir la orientación sexual propia, si bien esta experimentación suele silenciarse por temor a la presión social y al rechazo:

No lo sabe mi madre. Yo me he enrollao con una amiga mía, pero no porque me gustara, sino porque pillamos una borrachera impresionante, porque era la primera vez que yo bebía. Entonces, pues yo qué sé, y le digo: «iA que no te atreves?», pero somos mu amigas íntimas. Pero vamos, nos enrollamos y ya está. Le digo: «iA ti te ha gustao?». Dice: «No». Yo digo: «A mí tampoco». Y digo: «Pues ya está». Vamos, que fue una tontería de niños haciendo el tonto. (Bárbara, 15 años, clase obrera, caucásica)

Asimismo, los datos dan cuenta de que el grupo de amistad es el espacio de relaciones afectivas intensas por excelencia en la adolescencia. Cuando hay un problema entre dos jóvenes que forman parte de uno mismo, el grupo entero se hace partícipe de ello: «Ha creao conflicto en que, amigas de ella, porque ella lo trató mal a él, [...] han discutío con ella» (Jose, 15 años, clase obrera, caucásico). Asimismo, son frecuentes las "parejas recompuestas»", a pesar de existir una especie de norma implícita de posesión, honor y fidelidad por la que esas relaciones recompuestas entre miembros del grupo son penalizadas. Esta norma está fuertemente impresa en el imaginario adolescente:

Como estamos en el mismo grupo. [...] Ella era mi novia, la que está en la clase, luego cortó conmigo y salió con él. Nos peleamos yo y él. Y ahora él no está con ella y yo ahora me hablo con él. Yo ahora me hablo con ella y me hablo con él, pero él, sin embargo, no se habla con ella. [...] Hablamos tós bien menos ellos dos. [...] Yo, por ejemplo, tengo un amigo que es mu amigo mío, que somos como hermanos, desde que estamos en preescolar estamos juntos, y si él ha salío con una novia y la deja, yo a las dos semanas no voy a estar con ella. Y si salgo, sería discreto, no como él, que venía, a veces, venían ellos y se daban besos delante mía. Yo eso lo veo mal. (Jose, 15 años, clase obrera, caucásico)

Finalmente, el grupo sostiene otra regla implícita en referencia a las experiencias sexuales (también en Jones, 2010) desde un doble estándar de género: a las chicas les resta "capital simbólico", mientras que en el caso de los chicos es sinónimo de «virilidad» (Bourdieu, 2005):

Algunas niñas que son un poco putas, que a lo mejor llegan un día y se lían con uno, y al día siguiente, con otro, y al día siguiente, con otro. (Sergio, 15 años, clase media, caucásico)

Cuanto más ligues, es mejor, más macho eres. Tú me entiendes, ¿̇no? O... te lo tienes hasta que inventar pa que no quedes en ridículo. (Raúl, 17 años, clase obrera, mestizo)

9. Haciendo un uso libre del concepto de familias recompuestas de Giddens (2004). 


\subsection{Prácticas sexuales}

Se entiende aquí por prácticas sexuales todas aquellas relacionadas con la sexualidad como fenómeno social y relacional, en que el cuerpo puede estar implicado o no. Los datos procedentes de las entrevistas de este estudio dan muestra de una presión internalizada por las chicas, principalmente las de clase obrera, sobre la necesidad de «hacerlo bien», como también Skeggs (1997) analiza en su trabajo. Una chica respetable ha de saber mantenerse en su sitio e, igualmente, hacer que el chico se mantenga en el suyo, pues la sexualidad esporádica, sobre todo las prácticas coitales, están socialmente penalizadas (ver también Holland et al., 1994). En cambio, la pareja estable es el espacio legítimo para la práctica de una sexualidad progresiva socialmente aceptada:

Yo veía que me tocaba el culo. Digo: «Bueno, es mi novio. ¿Por qué no?». Hombre, no le dejaba tocar mis partes de aquí, porque yo se lo decía, yo le decía que me respetara y tó. (Bárbara, 15 años, clase obrera, caucásica)

Por su parte, los chicos de las entrevistas construyen un discurso con contradicciones. Por un lado, se premia la poca experiencia sexual de las chicas; por otro, los chicos se quejan de ello:

Con mis años, como tú no te eches novia, es mu difícil que chingues, porque, con mis años, tú te echas una novia y tú te tiras tus ocho meses con ella y ya po cae. Y si estás de un rollo de una noche o estás de rollo, po esas no siempre caen. [...] Porque son niñas a lo mejor de diecisiete años o por ahí. Si tienes veintitrés años, porque mi primo me lo ha dicho: «Tú vas a la discoteca y tú ya no te lías, tú te la llevas, te la tiras y ya está», porque ya eres más grande, pero ahora, con estos años, es más difícil hacer eso. (Tony, 17 años, clase media, mestizo)

Discursos como el de la cita anterior, presentes en muchos de los chicos entrevistados, permiten esbozar la imagen que construyen los adolescentes sobre la sexualidad. Un placer deseado, pero inaccesible a su edad, donde la chica es mero objeto sexual al que el chico "se tira» si tiene suerte y ella "cae». La chica es concebida en términos patriarcales de pasividad sexual y cosificación. El chico tiene, entonces, que convencerla:

A lo mejor, pa tirarme a una que era un cañón, me tenía que tirar la vida. [...] Me costaba a lo mejor estar una fiesta entera pa que cayera. Pues que le den por culo. Yo tenía mi grupo de amigos y ya pasaba de ella, y yo creo que cuanto más pases de ellas, mejor. (Tony, 17 años, clase media, mestizo)

Este doble estándar de género que atraviesa el imaginario afectivosexual adolescente es hallado también por Carmona (2011) en su estudio. Los datos analizados aquí sitúan a las chicas en el punto de mira, donde la honra es un bien preciado que les confiere valor social o las pone en cuestión. Así, las chicas se muestran en las entrevistas en la disyuntiva de resolver el conflicto entre ser 
sexualmente activas y deseables, para gozar de prestigio en el grupo de amistad, pero sin llegar a perderlo por perder el honor debido a un exceso de actividad sexual. Un criterio negativo para las chicas, al que no se ven sometidos los chicos en ningún caso:

Es una niña más suelta. [...] Una niña de esta que se enrolla con un niño cuando lo ve. Ella querrá hacerlo así, yo qué sé. A veces, ha tenío novios formales y eso. Yo, porque ella se enrolle con un niño así no le voy a decir «ya no soy tu amiga». Tampoco es eso. (Bárbara, 15 años, clase obrera, caucásica)

CHICA: ¿Qué le veis?

CHICO: ¿Que qué le veo? Que es una puta. Que nos la follamos entre tres y la niña que se deja. ¿Pues qué le vamos a ver? Eso te lo digo a ti, se lo digo a la otra, a..., y puede ser que me des una hostia.

CHICA: Pues sí.

CHICO: Se lo dices a ella y va directa pa mi casa, pero corriendo.

(Conversación reproducida por Belén, 15 años, clase media, caucásica)

Los chicos, pero también las chicas de este estudio, mantienen esa dicotomía entre las mujeres «buenas», que no tienen apetito ni realizan prácticas sexuales, y las «malas», que son promiscuas (Simón, 1997). A esta forma de presión sobre las chicas se suma, también, la ejercida directamente por los chicos para mantener relaciones sexuales o para imponer su voluntad sobre ellas, como denuncian también Holland et al. (1994):

El niño tenía ya 19 años y decía: «A mí eso es lo que menos me importa. Yo quiero estar contigo no por lo otro [practicar el coito], sino que yo quiero estar contigo por lo que eres tú». [...] Las niñas de mi clase, yo sé que muchas veces les han dicho: «Si no haces esto, pos lo dejamos». A mí eso, por ejemplo, no me lo han dicho nunca. Yo qué sé, yo creo que por esa parte, que no me han, que no me han forzao ni ná. (Inma, 16 años, clase obrera, caucásica)

Las entrevistas muestran la pervivencia de la vieja creencia en una mayor disponibilidad de los chicos para la práctica sexual, mientras que las chicas tienen menos deseo sexual o son más pasivas (también en Jones, 2010; Carmona, 2011). De ahí esa tendencia, entre las adolescentes y los adolescentes del estudio, a que el chico de la pareja espere a que la chica esté preparada para mantener relaciones coitales, y la chica se vea sometida a la presión por mantenerlas. Esta cuestión aparece en los datos como ocupando el lugar central de las relaciones sexuales entre adolescentes. Las chicas portan el discurso del recato y los chicos, el de la promiscuidad. Pero si las chicas han de mantenerse asexuales y los chicos, activos, ¿̇ómo podrán chicas y chicos entenderse correctamente en sus relaciones afectivosexuales? Este modelo es contradictorio y reproduce un doble estándar de género, lo que problematiza las relaciones entre adolescentes. Las chicas, en tanto que objeto de mayor juicio moral, destacan en sus entrevistas la importancia de tener una pareja que respete sus decisiones, sus ritmos. 
Las presiones a que dicen verse sometidas son una preocupación continua en sus relaciones y las muestran como una preocupación central en ellas. Ahora bien, las entrevistas revelan también experiencias de chicos que, por amor a su pareja y miedo a perderla, se adaptan a las necesidades y a los ritmos de sus parejas. En cualquier caso, en las entrevistas se observa una creencia común, compartida, sobre la existencia de una diferencia natural, genital, entre mujeres y hombres, que justifica la prisa, el deseo y la proclividad de los hombres a la práctica sexual, ausente en las chicas, como también Carmona (2011) halla en su estudio:

Me dejó por eso. Me dijo: «Es que como no lo hemos hecho». [...] Y yo le dije: «Pero, vamos a ver, si sabes que a mí me da igual». [...] «Yo en eso no te meto prisa porque lo entiendo, ¿no? Es que no es lo mismo yo que tú». (Paco, 17 años, clase media, caucásico)

\subsection{Prácticas afectivas y formación de parejas}

Aunque se hayan separado aquí para sistematizar el análisis, las prácticas afectivas y las sexuales están intrínsecamente relacionadas en el romance adolescente. Las entrevistas evidencian una diferencia fundamental entre tener "un rollo», una relación esporádica, o una pareja, una relación estable. El rollo es un tipo de pareja eventual, que permite autonomía y libertad individual, al mismo tiempo que se mantiene una relación afectivosexual en que es más fuerte el vínculo sexual que el afectivo. El tipo de pareja estable basa su estabilidad en el equilibrio entre la dimensión afectiva y la sexual. El rollo, o transa (Jones, 2010), no implica compromiso, ni dar explicaciones ni fidelidad. La pareja es mucho más vinculante en todos los sentidos:

En uno así también coges más confianza al estar con ella, pos te gusta, estás... No que en la otra es un rollo, pos dices: «Es un rollo, pos ya está». Tampoco te importa mucho. (Jorge, 16 años, clase obrera, caucásico)

Las entrevistas ofrecen una imagen de las relaciones afectivas en el romance adolescente caracterizadas por el conflicto. Como se veía también al analizar las dinámicas afectivosexuales en el seno del grupo de amistad, celos, posesión y control son, a menudo, las formas que adopta la afectividad en la pareja adolescente:

Discusiones porque no te pongas esa farda, no vayas con tus amigos a este lao. Te peleas porque no puedes ir con tus amigos porque se mosquea. Que, de pronto, leen el móvil. Que, a lo mejor, tengas un móvil de una niña y te lo borre. (Jose, 15 años, clase obrera, caucásico)

Los datos muestran mayor conflictividad cuando chocan los principios y los valores nucleares internalizados durante la socialización, sobre todo familiar. De las dos parejas que existen en el momento de hacer las entrevistas, una en 
cada estudio de caso, la de clase obrera ofrece ejemplos especialmente ilustrativos de dicha cuestión. A lo largo de su entrevista, el chico construye un discurso caracterizado por valores patriarcales, tradicionales y conservadores. Por su parte, la chica construye un discurso fruto de una socialización familiar más liberal, abierta, democrática e igualitaria. Cada miembro de esta pareja adolescente porta, pues, una imagen diferente de lo que es una relación de pareja ${ }^{10}$.

Para la sociología que investiga esta temática, el reto de las parejas en la sociedad actual radica en compatibilizar libertad e independencia individual con entrega y sentido de pertenencia (Beck y Beck-Gernsheim, 2001; Giddens, 2004; Bauman, 2005; Bourdieu, 2005; Castells y Subirats, 2007; Venegas, 2013a). Entre el grupo de adolescentes de esta investigación, el amor se muestra, a menudo, como paradoja entre un flujo de emociones, afectos y sentimientos positivos que enriquecen a la pareja, pero que suele incurrir también en control, dependencia y dominación o subordinación con un sesgo de género:

Ella sabe que me da coraje. Que no es lo mismo una niña que un niño. Yo a un amigo se lo cuento tó y él piensa lo mismo de ella. Y yo noto que no me quiere, porque si me quisiera de verdad, ya vería lo que hace. (Raúl, 17 años, clase obrera, mestizo)

Son bastantes los sujetos de la investigación que tienen pareja en el momento de hacer la entrevista o que la han tenido con anterioridad. En algunos casos, se trata de una pareja de la infancia. En otros, son parejas adolescentes, donde la sexualidad cobra mayor presencia y visibilidad y ocupa un espacio central: «Dicen que es el cincuenta por ciento de la relación y yo no sé si es verdad o es mentira, pero si no funciona eso...» (Tony, 17 años, clase media, mestizo).

Como tendencia generalizada en esta investigación, cuando las entrevistas a los chicos han llegado a un grado de complicidad y sinceridad suficientes, los chicos han roto con la norma social que impide a los hombres mostrar sus sentimientos, para reconocer que el amor es cosa de personas:

Me enamoré de una niña, ¿̇no? Yo qué sé, estuve saliendo con ella y cambié mucho. Antes estaba con mis amigos y ya no estaba. Antes me vestía de chándal y tó eso, ahora no, ahora quería ir siempre mu bien arreglao, quería estar siempre con ella. [...] Cambiamos mucho cuando queremos a alguien. Estás con tus amigos y te comportas como un niño chico. A lo mejor tienes novia y te comportas como un tío de 40 años. Es la verdad, mi madre me lo decía. Cuando estuve saliendo yo con una niña, pasaba por la puerta y me decían: «Niño, estás apollardao. Estás despistao, estás distraío». (Sergio, 17 años, clase obrera, caucásico)

Las entrevistas de los chicos llegan incluso a reconocer que, en el amor, los hombres también sufren:

10. Véase aquí la primera cita recogida en el apartado «3.1. Clase, género y etnia». 
Yo se lo dije, que lo había pasao mu mal, ¿no? Lo que pasa es que se lo dices a una niña y como que parece que las que tienen únicamente sentimientos son ellas.<smiles></smiles>

Hubo otro día que intenté con mi novia, bueno, no lo intenté, pasó así..., y no tenía preservativo ni ná. [...] La otra vez, lo intentamos y no entró, [...] estamos tumbaos y me dice, dice: "Es que te tengo que decir una cosa». Me vuelvo y yo: «Tú verás lo que me va a decir», y dice: "Quiero que sea contigo. ¿Me quieres?». Me quedo así y al principio no lo pillé y de pronto no lo pillo y dice: "Que sí, que quiero que sea contigo», y de seguidas me vino un flash así y dije: «Hostias, no sé qué». Muchas veces había soñao con eso, pero nunca creía que me lo iba a decir ese día. Y me dice: «Que quiero que sea contigo». Y yo: «'Tú estás segura?». Y me dice: «Sí». Y digo: «Estás segura?». «iQue sí, que sí!» Y lo intentamos y no pasó na y luego justamente el día que no lo intentamos no sé qué, que la tenía casi dentro, sabes, tenía la puntilla aún así y na, le dije que no. Bueno, no le dije que no, la retiré, ¿̇sabes? ¿Me entiendes? [...] Tú empiezas haciendo cosillas, ¿̇no? Así, como de niños, no sé qué, pero luego, ya a lo que pasas es algo más serio, no es... cualquier tontería y ya es algo más. Es como un paso más. (Paco, 17 años, clase media, caucásico)

Por tanto, la «masculinidad hegemónica» (Connell, 1987), o «virilidad como nobleza» (Bourdieu, 2005), establece los valores y las normas del modelo de masculinidad dominante en que se socializa a los hombres. Sin embargo, en la intimidad de la política afectivosexual, los chicos reconocen sentir, amar y sufrir, porque son actos humanos. Las marcas de género imponen modelos, se puede llorar o no, expresar los sentimientos o no, sin embargo esas marcas no dan cuenta de una esencia masculina y otra femenina, más bien al revés. Son imposiciones sociales y culturales que prescriben prácticas generizadas.

El enamoramiento aparece en las entrevistas como estado de metamorfosis en la cotidianeidad de una persona. Cuando alguien se enamora, los ritmos de sus prácticas, en general, se ven alterados para adaptarlos a los de la persona amada, si bien también aquí se distingue entre la pareja estable y la eventual, prefiriendo el segundo tipo, porque la adolescencia se entiende como un momento para vivir, conocer, ser libre e independiente y disfrutar, y el compromiso queda relegado al futuro:

Yo no me he enamorao, porque si yo hubiera estao enamorao, me seguiría gustando esa persona. A lo mejor no es que te enamores, sino que te gusta esa persona dos meses, cortas, y al mes ya te gusta otra. Si estuviera enamorao no me pasaría eso [...]. Te atrae físicamente [...]. Y si te enamoras, yo qué sé, en mu pocos casos. [...] Pregúntale a cualquier niña, le gusta hoy un niño, y dentro de un mes le gusta otro. Y a un niño le gusta hoy una y mañana otra, eso es así. (Jose, 15 años, clase obrera, caucásico)

La otra pareja de este estudio, en el caso de clase media, permite también hacer un análisis comparativo de las interpretaciones que chica y chico hacen de su relación, donde se ponen en evidencia las marcas de género. El chico plantea que: 
Creo que ni me gustaba. Fue también un poco, no pa olvidarme de mi ex, porque yo ya lo tenía asumío, pero fue también un poco pa salir, pa decir: «Bueno, ya soy libre» $[. .$.$] . No me gusta y a parte porque no me daba na tampoco, yo$ la veía mu paraílla y yo po no soy paraíllo [...]. Digo: «Con quien quieras, que yo ya sabes que yo es rollo». Y se lo dejé bien claro, entre comillas rollo, y punto y se acabó [...]. Y me dice: «Es que el otro me dice cosas bonitas». «Coño! Yo también te puedo decir cosas bonitas», y entonces le solté una cosa, en las clases parecía que es que me había enamorao de ella y digo: "A ver, que no, que es rollo, que yo te dije eso». (Alberto, 15 años, clase media, caucásico)

Por su parte, la chica afirma que:

Dije: «Va a ser un rollo y ya está», pero fueron más días. [...] Un día le faltó recitarme un poema. Te lo prometo, fue una cosa impresionante y, claro, al día siguiente, que yo no me lo explico si no es que es un mentiroso. [...] Luego, el día que pasamos juntos, te lo prometo, el más intenso y el más bonito. (Victoria, 15 años, clase media, caucásica)

Para cada miembro de esta pareja la relación tiene un significado diferente. Su interpretación, lejos de ser individual o aislada, refleja los modelos de género en relación con el amor. El chico sostiene el discurso de la promiscuidad como criterio de virilidad. La chica sostiene la ideología del romance que ha definido, históricamente, el modelo de feminidad (el amor romántico), al que apuntan también otras investigaciones (McRobbie, 1978; Holland y Eisehnart, 1990; Carmona, 2011). Él se muestra enamorado como estrategia de conquista para «un rollo». Para ella, esas palabras, su actitud y su comportamiento son muestras de amor que podrían llevar a consolidar la relación. Sin embargo descubre que era solo una farsa para tener relaciones sexuales con ella. Por eso no solo se siente engañada, defraudada y desconcertada, sino también presionada para hacer algo que no quiere. A menudo, las chicas del estudio relatan esta presión de los chicos para tener relaciones coitales con ellas sin que ellas estén seguras o lo deseen (también en Jones, 2010). Pese a todo, la chica justifica la actitud del chico aludiendo a discursos biologicistas sobre la tendencia más pasiva de las mujeres y más activa de los hombres respecto a la sexualidad:

El quería así, algo más, y yo no... La parte sexual. [...] Si hubiera estado más tiempo saliendo o algo... Pero yo, así al tun-tun, mi primera vez y con un rollo que llevo. Él no me quiere ni yo a él. [...]. Yo dije: «Si quieres algo más, que te buscas a otra». [...] «Bueno, yo espero» [...]. Y al día siguiente me dijo: "Mira, no...». Yo me quedé tó pillá. [...] Me molesta pero como las niñas somos más cerradas para eso y ellos más..., pues yo lo entiendo. Fastidia pero lo entiendo. (Victoria, 15 años, clase media, caucásica)

\section{Conclusiones}

Este trabajo ha buscado contribuir al estudio sociológico de las relaciones afectivosexuales en la adolescencia partiendo de las pocas investigaciones previas 
existentes (McRobbie, 1978; Willis, 1988; Holland y Eisenhart, 1990; Gómez, 2004; Urrea et al., 2006; Clair, 2007a, 2007b; Jones, 2010; Carmona, 2011), la mayoría de las cuales hablan de romance adolescente.

En base a ello, este trabajo, a diferencia de los primeros (McRobbie, 1978; Willis, 1988; Holland y Eisenhart, 1990), toma las relaciones de género como unidad de análisis y las entiende, siguiendo la literatura feminista (Connell, 1987, 2002; Butler, 1997; Skeggs, 1997), como mediadas por el poder. De ahí que introduzca la expresión política afectivosexual para referirse al romance adolescente como objeto de estudio sociológico. Así, la política de las relaciones afectivosexuales en el romance adolescente se define como espacio social y cultural constituido por una serie de dimensiones tales como la cultura de clase, género y etnia, el grupo de amistad, la atracción sexual, las prácticas sexuales, las prácticas afectivas y la formación de pareja, tal como han sido analizadas en el apartado anterior, con el objetivo de investigar estas dimensiones para conocer los modelos de masculinidad y feminidad presentes en ello y, consecuentemente, las relaciones y prácticas afectivosexuales que se establecen en torno a estos modelos en términos de poder y (des)igualdad.

Junto a los análisis hechos por estudios anteriores desde las perspectivas de la clase social y el género, este trabajo ha incorporado también la pertenencia étnica y, a diferencia de los clásicos que han estudiado a los chicos, o a las chicas, este ha analizado las relaciones de género. Asimismo, a diferencia de los estudios anteriores, esta investigación parte de la praxis de la educación afectivosexual para investigar la política afectivosexual como objeto de estudio sociológico a través de una metodología de investigación acción.

A tenor de los datos analizados en el apartado anterior, es posible concluir señalando la reproducción de un modelo de romance adolescente donde masculinidad y feminidad se complementan según una lógica patriarcal, desigualitaria, en las relaciones afectivosexuales adolescentes investigadas. Esto es así en tanto que los datos analizados muestran una tendencia general entre los chicos a identificarse con la masculinidad hegemónica (Connell, 1987) o viril (Bourdieu, 2005), mientras que las chicas tienden mayoritariamente a identificarse con la feminidad enfatizada (Connell, 1987), basada en el ideal del amor romántico (Luengo y Rodríguez, 2009).

El romance adolescente analizado aquí muestra un tipo de relación en que resulta difícil establecer una comunicación fluida en la pareja, basada en el diálogo abierto, exento de miedos, tabúes, estereotipos, cesiones ante presiones, y que capacite para tomar decisiones reflexivas y críticas para actuar en consecuencia.

Estas conclusiones podrían servir de base para plantear que el principal reto que tiene la población adolescente para formar parejas más democráticas e igualitarias radica en aprender a crear un espacio de consenso entre la libertad y la independencia, por un lado, el compromiso, por otro, y el respeto mutuo, como principios fundamentales en la pareja, valores que también la literatura revisada señala como grandes retos para las parejas actuales (Beck y Beck-Gernsheim, 2001; Bauman, 2005). 
Dando un paso desde el análisis sociológico hasta un posicionamiento feminista, cabría apoyarse en la evidencia empírica analizada como fundamento científico sobre el que justificar la necesidad de desarrollar políticas de educación afectivosexual, inexistentes en España (Parker et al., 2009), para promover, desde la propia educación formal, un modelo de relaciones inspirado en valores democráticos, el respeto, la igualdad, el reconocimiento de la diversidad y la defensa de la justicia social. Una ausencia de educación afectivosexual, o una forma incorrecta de la misma, deriva en una política afectivosexual basada en temores, estereotipos y falsas creencias, como han puesto de manifiesto los datos analizados en este artículo.

Ello suele conducir a situaciones de conflictividad en la pareja o, incluso, a problemas mayores, como la violencia de género, como muestran los estudios publicados recientemente en España (Díaz-Aguado y Carvajal, 2011; DíazAguado, 2013; Lourido, 2013). La Ley de salud reproductiva y sexual y de interrupción voluntaria del embarazo, aprobada en España en 2010 (Jefatura del Estado, 2010), incluía, entre sus principios y propuestas, esta necesidad de implementar la educación afectivosexual desde el propio sistema educativo. Los cambios políticos posteriores han dejado este tema paralizado por el momento. Será necesario, pues, continuar trabajando en esta línea de investigación en sociología.

\section{Referencias bibliográficas}

Barragán, Fernando (1999). Programa de Educación Afectivo-Sexual: Educación Secundaria. Sevilla: Junta de Andalucía.

BARTKY, Sandra Lee (1988). «Foucault, Femininity, and the Modernization of Patriarchal Power». En: Diamond, Irene y QuinbY, Lee (eds.). Feminism and Foucault: Reflections on Resistance. Boston: Northeastern University Press.

Bauman, Zygmund (2005). Amor líquido: Acerca de la fragilidad de los vínculos humanos. Madrid: Fondo de Cultura Económica.

BECK, Ulrich y BECK-GERNSHEIM, Elisabeth (2001). El normal caos del amor. Barcelona: Paidós.

- (2012). Amor a distancia: Nuevas formas de vida en la era global. Barcelona: Paidós.

BERG, Bruce L. (2001). Qualitative Research Methods for the Social Sciences. Boston: Allyn and Bacon.

BouRDIEU, Pierre (2005). La dominación masculina. Barcelona: Anagrama.

BUTLER, Judith (1997). The psychic life of power: Theories in subjection. Stanford: Stanford University Press.

CARmona, Mariela (2011). «¿Negocian las parejas su sexualidad?: Significados asociados a la sexualidad y prácticas de negociación sexual». Estudos Feministas, 19 (3), 801-821. <https://doi.org/10.1590/s0104-026x2011000300008>

Castells, Manuel y Subirats, Marina (2007). Mujeres y hombres: ¿Un amor imposible? Madrid: Alianza Editorial.

CLAIR, Isabelle (2007a). «La division genrée de l'expérience amoureuse: Enquête dans des cités d'habitat social». Sociétés \& Représentations, 2 (24), 145-160. $<$ https://doi.org/10.3917/sr.024.0145> 
- (2007b). «Amours adolescentes: Dans des quartiers d'habitat social». Informations Sociales, 8 (144), 118-125.

Connell, Robert William (1987). Gender and Power: Society, the Person, and Sexual Politics. Stanford: Stanford University Press.

- (2002). Gender. Cambridge: Polity Press.

DíAZ-AguAdo, M. ${ }^{a}$ José (2013). La evaluación de la adolescencia española sobre la igualdad y la prevención de la violencia de género. Madrid: Ministerio de Sanidad, Política Social e Igualdad.

Díaz-Aguado, M. ${ }^{a}$ José y Carvajal, M. ${ }^{a}$ Isabel (2011). Igualdad y prevención de la violencia de género en la adolescencia. Madrid: Ministerio de Sanidad, Política Social e Igualdad.

ElliotT, John (1993). El cambio educativo desde la investigación-acción. Madrid: Morata.

- (1994). La investigación-acción en educación. Madrid: Morata.

FoucaulT, Michel (1989). Historia de la sexualidad. Vol. I. Madrid: Siglo XXI.

GidDENS, Anthony (2004). La transformación de la intimidad: Sexualidad, amor y erotismo en las sociedades modernas. Madrid: Cátedra.

GÓMEZ, Jesús (2004). El amor en la sociedad del riesgo. Barcelona: El Roure.

GorrotXategui, Mayte y Haro, Isabel M. ${ }^{a}$ de (1999). Materiales didácticos para la prevención de la violencia de género. Málaga: Gobierno de Andalucía.

HolfVE-SABEL, Mary-Anne (2011). «Gender attitudes in school have changed mainly in peer relational factors over a period of 35 years». Gender and Education, 23 (1), 73-86.

<https://doi.org/10.1080/09540251003675466>

Holland, Dorothy C. y EISENHART, Margaret A. (1990). Educated in Romance. Londres: University of Chicago Press.

Holland, Janet; Ramazanoglu, Caroline; Sharpe, Sue y Thomson, Rachel (1994). "Power and Desire: The Embodiment of Female Sexuality». Feminist Review, 46, 21-38. <https://doi.org/10.2307/1395415>

JEFATURA DEL ESTADO (2010). «Ley Orgánica 2/2010, de 3 de marzo, de salud sexual y reproductiva y de la interrupción voluntaria del embarazo». Boletín Oficial del Estado, 55 (4 de marzo de 2010), 21001-21014.

JONES, Daniel Eduardo (2010). «Bajo presión: Primera relación sexual de adolescentes de Trelew (Argentina)». Revista Estudos Feministas, 18 (2), 339-358. <https://doi.org/10.1590/s0104-026x2010000200004>

Kemmis, Stephen (2007). "Action Research as a Practice-Changing Practice». En: Investigación-acción participativa: Reflexiones y experiencias. Segovia: Escuela Universitaria de Magisterio de Segovia y Collaborative Action-Research Network. Recuperado de <http://hera.fed.uva.es/congreso/comunicaciones.htm> [Consulta: 22 junio 2008].

KORKIAMÄKI, Riikka (2011). «Support and Control among "Friends" and "Special Friends”: Peer Groups' Social Resources as Emotional and Moral Performances amidst Teenagers». Children \& Society, 25, 104-114. <http://dx.doi.org/10.1111/j.1099-0860.2009.00262.x>

LOURIDO, Mariola (2013). «El 60\% de las chicas recibe insultos machistas de parejas y amigos en el móvil». Cadena Ser (18 de noviembre de 2013). Recuperado de <http://www.cadenaser.com/sociedad/articulo/chicas-recibe-insultos-machistasparejas-amigos-movil/csrcsrpor/20131118csrcsrsoc_2/Tes>. 
Luengo, Tomasa y Rodríguez, Carmen (2009). "El mito de la "fusión romántica": Sus efectos en el vínculo de la pareja». En: AEPS (ed.). Anuario de Sexología, 11, 19-26.

McRobBie, Angela (1978). «Working Class Girls and the Culture of Feminity». En: Women Take Issue. Londres: Hutchinson / Centre For Contemporary Cultural Studies.

Messer, Lynne C.; Shoe, Erin; Canady, Megan; Sheppard, Barbara K. y Vincus, Amy (2011). «Reported adolescent sexual norms and the development of a social marketing campaign to correct youth misperceptions». Journal of Children and Poverty, 17 (1), 45-63. <https://doi.org/10.1080/10796126.2011.539197>

PARKER, Rachael; Wellings, Kaye y LAZARUS, Jeffrey W. (2009). «Sexuality education in Europe: An overview of current policies». Sex Education: Sexuality, Society and Learning, 9 (3), 227-242. <http://dx.doi.org/10.1080/14681810903059060>

REISS, Michael (2005). "Managing Endings in a Longitudinal Study: Respect for Persons». Research in Science Education, 35, 123-135. <https://doi.org/10.1007/s11165-004-3436-z>

Rubin, Gayle (1975). "The traffic in women: Notes on the "Political Economy" of sex». En: ReITER, Rayna R. Toward and anthropology of women. Londres: Monthly Review Press, p. 157-210.

Simón, M. Carmen (1997). "Cuerpo pensado, cuerpo vivido: Normas y transgresiones en la España del siglo XIX». Arenal, 4 (1), 39-57.

SKEGGS, Beverly (1997). Formations of Class and Gender: Becoming Respectable. Londres: SAGE Publications.

Soanes, Catherine; Stevenson, Angus (2008). Concise Oxford English Dictionary. Oxford: Oxford University Press.

Urrea, Fernando; Herrera, Hernán Darío; Botero, Waldor y ReYes, José Ignacio (2006). "Afecto y elección de pareja en jóvenes de sectores populares de Cali». Estudos Feministas, 14 (1), 117-148. <https://doi.org/10.1590/s0104-026x2006000100008>

URRUZOLA, M. ${ }^{a}$ José (1991). ¿Es posible coeducar en la actual escuela mixta?: Una programación curricular de aula sobre las relaciones afectivas y sexuales. Bilbao: Maite Canal.

VALles, Miguel (1997). Técnicas cualitativas de investigación social. Madrid: Síntesis.

VENEGAS, Mar (2006). "La mirada normativa del "otro": Representaciones del cuerpo femenino y construcción de la identidad corporal a través de la experiencia del cuerpo como espacio de sumisión y resistencia». En: MuÑOZ, Ana M.a; GrEGORIO, Carmen y SÁNCHEZ, Adelina (eds.). Cuerpo de mujer: Miradas, representaciones e identidades. Granada: Universidad de Granada.

- (2010). «La maldición de ser niña: Estructuralismo, postestructuralismo y teoría de la práctica en género y sexualidad». Papers: Revista de Sociología, 95 (1), 139-156. <https://doi.org/10.5565/rev/papers/v95n1.675>

- (2011a). «Un modelo sociológico para investigar las relaciones afectivosexuales». Revista Mexicana de Sociología, 73 (4), 559-589.

- (2011b). «Educación afectivosexual y coeducación en secundaria». En: JiMÉNEZ, Magdalena; RoBles, Victoria; AÑAÑos, Fani y PozO, Francisco J. (eds.). Educación para la igualdad: Reflexiones y propuestas (edición digital en CD-ROM). Granada: Natívola. 
- (2011c). «La investigación acción educativa en educación afectivosexual: Una metodología para el cambio social». EMPIRIA: Revista de Metodología de Ciencias Sociales, 21, 39-61. $<$ https://doi.org/10.5944/empiria.21.2011.859>

- (2013a). Amor, sexualidad y adolescencia: Sociología de las relaciones afectivosexuales. Granada: Comares.

- (2013b). «Sex and relationships education and gender equality: Recent experiences from Andalusia (Spain)». Sex Education: Sexuality, Society and Learning, 13 (5), 573-584.

<http://dx.doi.org/10.1080/14681811.2013.778823>

- (2014). «Investigar las relaciones afectivosexuales: El diseño de un cuestionario abierto». EMPIRIA: Revista de Metodología en Ciencias Sociales, 28, 183-212. $<$ https://doi.org/10.5944/empiria.28.2014.12126>

- (2017). «Devenir sujeto: Una aproximación sociológica». Convergencia: Revista de Ciencias Sociales, 73 (1), 13-36.

WiLlis, Paul (1988). Aprendiendo a trabajar. Madrid: Akal, 1977.

- (2003). «Foot Soldiers of Modernity: The Dialectics of Cultural Consumption and the 21st-Century School». Harvard Educational Review, 73 (3), 390-415.

Wolf, Naomi (1991). El mito de la belleza. Barcelona: Emecé Ediciones.

YOUDELL, Deborah (2006). «Subjectivation and performative politics — Butler thinking Althusser and Foucault: Intelligibility, agency and the raced-nationed-religioned subjects of education». British Journal of Sociology of Education, 27 (4), 511-528.

$<$ https://doi.org/10.1080/01425690600803160> 